\title{
A Compact Integrated Small Disk Monopole Antenna with DGS for Wireless Applications
}

\author{
M. Chandrasekhar, M.Suneel Raja
}

\begin{abstract}
The structure of a compact Micro strip feed circular monopole antenna working in the frequency range of $(2.5 \mathrm{GHz}-4 \mathrm{GHz})$ and wideband of frequency ranging from $4.9 \mathrm{GHz}$ to $19.93 \mathrm{GHz}$ is proposed in this paper. Using a circular radiating monopole with terrible ground wideband frequency operation is possible. Two frequency bands can be accomplished by separating the middle part of the patch and further engraving a circular arc with radius $2 / 2$ from it. An FR4 substrate with $\square r=4.4$ and a loss tangent of 0.02 was utilized to realize and simulate this antenna. It can be operated in both the frequency bands $2.5-4 G \mathrm{Gz}$ and 4.9-19.93G Gz [wideband] possessing less than $-10 \mathrm{~dB}$ reflection coefficient. The whole WB and also in the low-frequency band as mentioned above shows a sturdy radiation pattern.
\end{abstract}

Keywords: Disk monopole MPA, Dual band, Radiation pattern, gain.

\section{INTRODUCTION}

$\mathrm{F}_{\text {or antenna designers, the task of modeling a simple and }}$ small size antenna that can be used for multiband communication is difficult. High gain, increased impedance bandwidth, and good radiation patterns are the required qualities of a multiband antenna. Many researchers have designed a huge number of antennas employing different shapes of defects in the ground plane [1-4]. Apart from existing extra resonant modes utilizing the concept of defected ground structures has been an eminent technique in limiting the dimensions of the antenna. Various patch antenna designs with different shapes of slits and slots have been proposed for dual-band applications. Slot loading techniques are used to reduce the size of an antenna and to produce multiband operation.

In recent years, the use of ultra-wideband (UWB) technology in wireless communication has been increased tremendously [5-9] to get increased bandwidth with less power consumption. For UWB applications a frequency band 3.1-10.6GHz was allotted by FCC, United States.UWB system is economical, less complicated and enables short-distance radio communication which offers high data rates.UWB antenna is a component in UWB system. But, at

Revised Manuscript Received on February 05, 2020.

* Correspondence Author

Dr M. Chandrasekhar, Assistant Professor, Department of Electronics and Communication Engineering, KITS Warangal, Telangana, India. Email: mcskmm@gmail.com

M.Suneel Raja, JRF, Department of Electronics and Communication Engineering, KITS Warangal, Telangana India.

(c) The Authors. Published by Blue Eyes Intelligence Engineering and Sciences Publication (BEIESP). This is an open access article under the CC BY-NC-ND license (http://creativecommons.org/licenses/by-nc-nd/4.0/) present there is a need for a single antenna with multiple frequency bands. These antennas exhibit an omni-directional high radiation pattern. Because of its huge channel capacity, minimum size and stress-free integration with distinctive wireless requirements. There is an urgent need of a small-sized antenna that may work on more than one radiation band which encompasses UWB range.

In this paper, a compact micro-strip feed circular monopole with operating frequency $(2.5 \mathrm{GHz}-4 \mathrm{GHz})$ and wideband (4.9-19.93GHz) frequency bands for wireless applications was designed. A modified circular radiating monopole with the destructive ground plane was used to achieve WB frequency operation. Further, with aid of slotting the vertical portion of the patch and then etching $\lambda / 2$ round arc from the patch, a dual-frequency band is accomplished. The proposed antenna is realized on FR4 with dielectric constant 4.4, loss tangent 0.02 and simulated using HFSS. Dual-band operation with frequency range $(2.5 \mathrm{GHz}-4 \mathrm{GHz})$ and wideband range $(4.9 \mathrm{GHz}-19.93 \mathrm{GHz})$ was achieved using this antenna whose reflection coefficient $<-10 \mathrm{~dB}$. It also provides stable radiation patterns for the above frequency bands.

\section{ANTENNA CONSTRUCTION}

The constructed antenna is a circular disk monopole as shown in fig.1. A frequency band notch was generated using microstrip open-loop resonators.

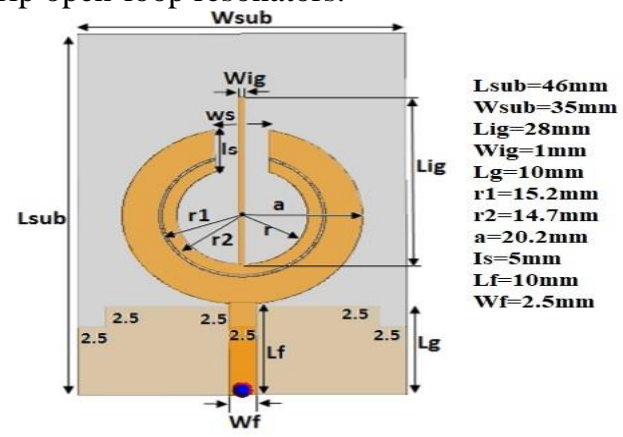

Fig.1.Antenna Construction

The disk and the resonator are etched on foreside and backside of the shape respectively [9-12]. To deliver a band notch, an excessive fine component is designed on the FR4. A Microstrip line is used to feed the monopole, which provides impedance of 50ohms. A range of numerous types of resonator might be used that allows creating the frequency notch band. By developing the gap length, the return loss might be progressed. 


\section{A. Current Distribution:}

Current distribution of small duration disk microstrip patch antenna with c fashioned DGS's are shown in Fig.2.

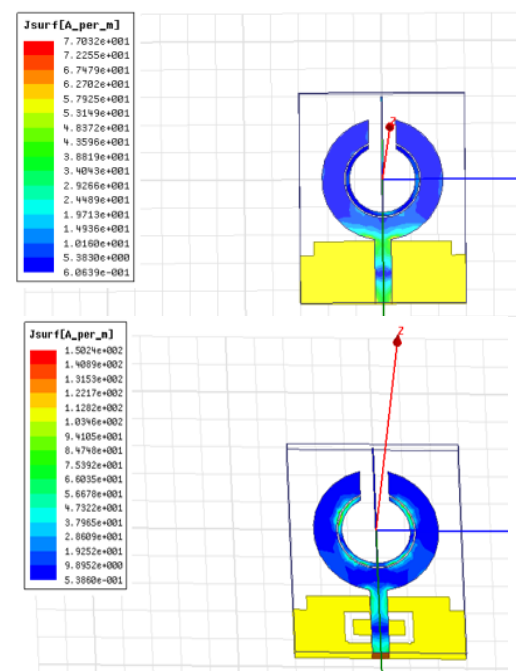

Fig.2. Current distribution of the constructed antenna

The current distribution in the antenna at a specific frequency is shown in fig.2. At the notch band center frequency, most of the monopole power couples to the resonator resulting in band notch.

\section{RESULTS}

The return loss of the constructed antenna is shown in fig.4. The band-notch middle frequency of $4.23 \mathrm{GHz}$ through simulation is acquired.

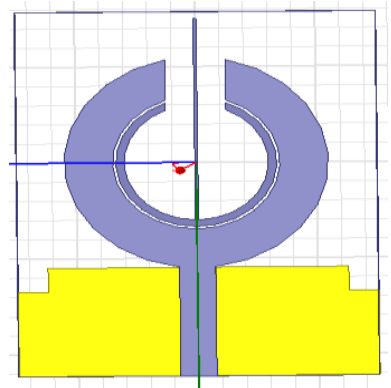

(a) Front View

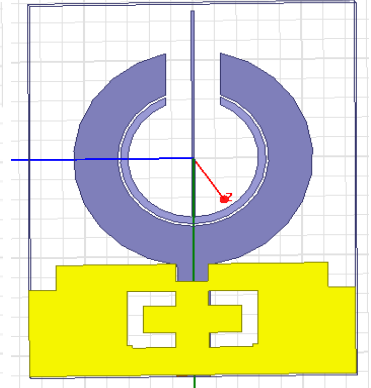

(b) back view
Fig.3. Design of antenna

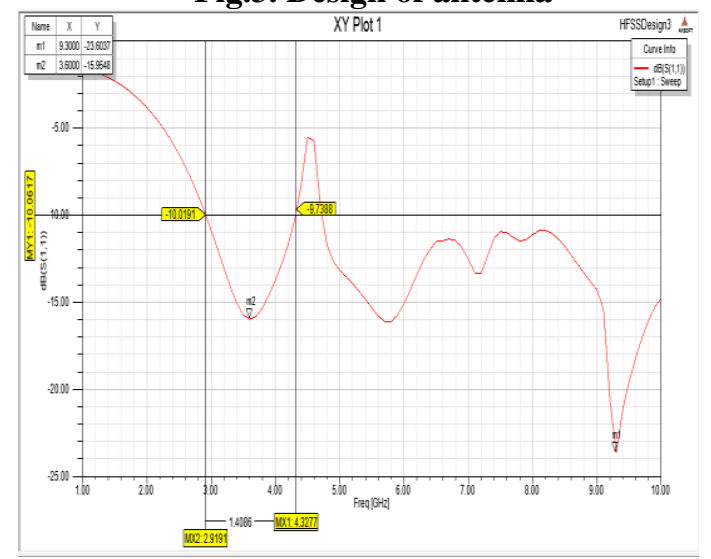

Fig . 4 The return loss of the antenna

The result suggests that the antenna offers an excessive rejection of signals in the notch band. It presents a return loss of $10 \mathrm{~dB}$ in $2.54 \mathrm{GHz}$ to $4 \mathrm{GHz}$ bandwidth which includes notch band. Above the notch band, the antenna offers a $10 \mathrm{~dB}$ return loss, which is enough for dual-band operations.Fig.6.

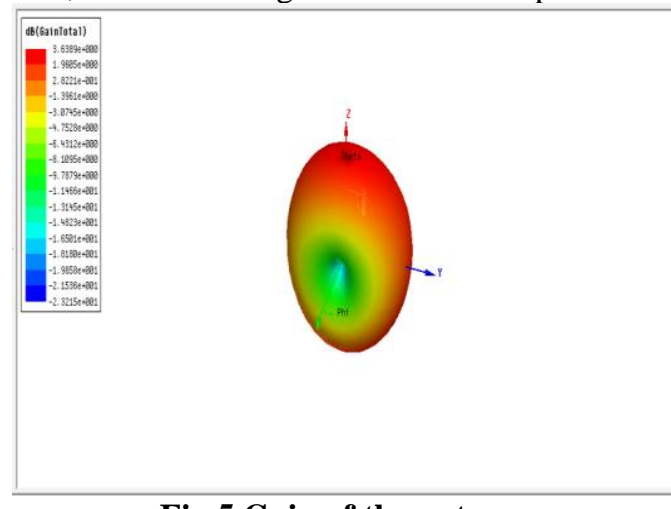

Fig.5 Gain of the antenna

Illustrate radiation pattern for the antenna that is constant over a given frequency.
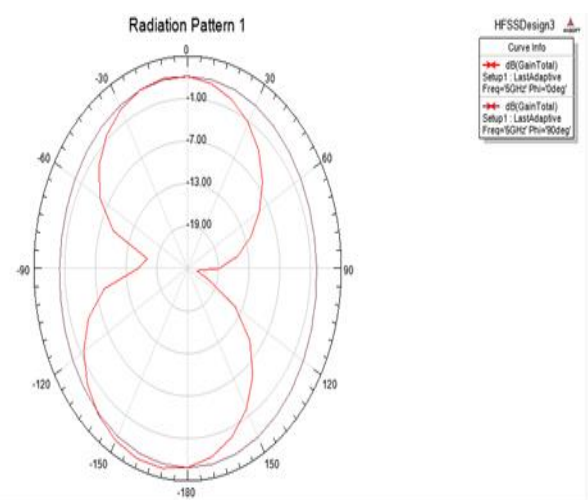

Fig.6. Radiation Pattern of antenna

\section{CONCLUSION}

A modest compact micro-strip feed circular monopole antenna using DGS approach has been illustrated in this paper. The proposed structure is simple in comparison to the existing complex structures. The designed circular patch antenna is simulated using HFSS simulator. The obtained outcomes of the designed antenna enable dual-band mechanism with S11 less than -10dB in addition to providing better radiation pattern, bandwidth, gain, and size. UWB requirements and FCC standardization are met by this bandwidth.

\section{REFERENCES}

1. Chandrakanta Kumar, "Microstrip Patch with Non proximal Symmetric Defected Ground Structure (DGS) for improved Cross-Polarization Properties over Principal Radiation Planes", IEEE Antennas and Wireless Propagation Letters, Vol.14, 2015.

2. Jingtao Zeng, "A Simple Wideband Magnetoelectrics Dipole Antenna with a Defected Ground Structure",IEEE Antennas and Wireless Propagation Letters,Vol.17, No.8, August 2018.

3. Dr.G.Anjaneyulu,"Design of a corner truncated patch antenna array with four elements for wireless applications",IEEE Xplore International Conference on Intelligent Sustainable Systems(ICISS 2019), ISBN:978-5386-7799-5

4. James R. Kelly And Peter Gardner" Band Notched UWB Antenna Incorporating A Microstrip Open-Loop Resonator" IEEE Transactions on Antennas and Propagation Letters, Vol.59, No.8, August 2011.

Published By:

Blue Eyes Intelligence Engineering 
5. Debatosh Guha, "Concentric Ring-Shaped Defected Ground Structures for Microstrip Applications", IEEE Antennas and Wireless Propagation Letters, Vol.5,2006.

6. B.R. Sanjeeva Reddy, " Compact Zigzag-Shaped-Slit Microstrip Antenna with Circular Defected Ground for Wireless Applications", IEEE Antennas and Wireless Propagation Letters, Vol.14,2015.

7. Wen Tao Li, "Inkjet Printing of Wideband Stacked Microstrip Patch Array Antenna on Ultrathin Flexible Substrates", IEEE Transactions on Components, Packaging and Manufacturing Technology, Vol.8, No.9, September 2018.

8. Tianjio Li, "Vertical Integration of High-Q Filter With Circularly Polarized Patch Antenna with Enhanced Impedance-Axial Ratio Bandwidth", IEEE Transactions on Microwave Theory and Techniques, Vol.66, No.6, June 2018.

9. Y.J.Sung, "A Reconfigurable Microstrip Antenna for Switchable Polarization", IEEE Microwave and wireless components letters, Vol.14, No.11, November 2004.

10. Sujoy Biswas, "Control of Higher Harmonics and Their Radiations in Microstrip Antennas using Compact Defected Ground Structures, IEEE Transactions on Antennas and Propagation, Vol.61, No.6, June 2013.

11. Dr.G.Anjaneyulu, Dr.T.A.N.S.N Varma, and J Siddartha Varma" A Compact Wide Band Polygon Patch Antenna for Ku-Band Applications" in Springer International Conference on Optical and Wireless Technologies(OWT 2018), Jaipur, Feb 10-11, 2018.

12. Dr.G.Anjaneyulu and J Siddartha Varma "Design and simulation of multi-band microstrip antenna Array for satellite applications" in IEEE International Conference on Electronics, Communication and Aerospace Technology (ICEC 2018), Coimbatore, Mar 29-31, 2018. 